\title{
SARS-CoV-2 RNA in Swabbed Samples from Latrines and Flushing Toilets: A Case-Control Study in a Rural Latin American Setting
}

\author{
Oscar H. Del Brutto, ${ }^{1 \star}$ Aldo F. Costa, ${ }^{2}$ Robertino M. Mera,${ }^{3}$ Derly Andrade-Molina, ${ }^{4}$ Bettsy Y. Recalde ${ }^{2}$ Héctor H. García, ${ }^{5}$ and \\ Juan C. Fernández-Cadena ${ }^{4}$ \\ ${ }^{1}$ School of Medicine, Universidad Espíritu Santo - Ecuador, Samborondón, Ecuador; ${ }^{2}$ Community Center, The Atahualpa Project, Atahualpa, \\ Ecuador; ${ }^{3}$ Department of Epidemiology, Gilead Sciences, Inc., Foster City, California; ${ }^{4}$ Omics Sciences Laboratory, Universidad Espíritu Santo - \\ Ecuador, Samborondón, Ecuador; ${ }^{5}$ Department of Microbiology, Center for Global Health, Instituto Nacional de Ciencias Neurológicas, \\ Universidad Peruana Cayetano Heredia, Lima, Perú
}

\begin{abstract}
Information about factors potentially favoring the spread of SARS-CoV-2 in rural settings is limited. Following a case-control study design in a rural Ecuadorian village that was severely struck by the pandemic, SARS-CoV-2 RNA were detected by real-time PCR in swabs obtained from inner and upper walls in 24/48 randomly selected latrines from casehouses and in 12/48 flushing toilets from paired control-houses ( $P=0.014$; McNemar's test). This association persisted in a conditional logistic regression model adjusted for relevant covariates (OR: 4.82; 95\% Cl: $1.38-16.8 ; P=0.014)$. In addition, SARS-CoV-2-seropositive subjects were more often identified among those living in houses with a latrine $(P=0.002)$. Latrines have almost five times the odds of containing SARS-CoV-2 RNA than their paired flushing toilets. Latrines are reservoirs of SARS-CoV-2 RNA, and it cannot be ruled out that latrines could contribute to viral transmission in rural settings. Frequent disinfection of latrines should be recommended to reduce the likelihood of fecal contamination.
\end{abstract}

Information about the role of social disparities on SARSCoV-2 spread in rural settings is mostly confined to editorial comments. ${ }^{1,2}$ Population-based surveys conducted by our group in community-dwelling middle-aged and older adults living in Atahualpa (rural Ecuador) disclosed a SARS-CoV-2 seroprevalence of $45 \%$ and an overall incidence rate ratio of 7.4 per 100 person months of potential virus exposure. ${ }^{3,4}$ In both studies, the use of latrines (as opposed to flushing toilets) was associated with SARS-CoV-2 seropositivity., ${ }^{3,4}$ In the same village, a shared latrine was a likely cause of incident SARS-CoV-2 contagion among several members of two otherwise unrelated families. ${ }^{5}$ Likewise, a study of social risks and SARS-CoV-2 infection in this population showed that poor home facilities were associated with SARS-CoV-2 infection. ${ }^{6}$ These data, together with findings from other investigators showing persistence of SARS-CoV-2 in human feces, ${ }^{7-9}$ motivated us to compare the presence of SARSCoV-2 RNA in latrines and flushing toilets in randomly selected houses of Atahualpa.

The study population is homogeneous regarding income and living styles. ${ }^{10}$ Although most houses have piped water, some use latrines instead of flushing toilets. Houses with latrines have an exposed plumbing system with faucets installed in the backyards. Latrines are located out of the houses, consist of small shelters with no ventilation, and do not have an incorporated pipe water sink or any other disinfecting fluids or alcohol-containing gels. By contrast, bathrooms with flushing toilets are larger than latrines and are located inside the house; they have piped water with an incorporated sink, and have ventilation windows (Figure 1).

A total of 411 inhabited houses (327 with flushing toilets and 84 with latrines) were identified during the aforementioned surveys in the village. ${ }^{3,4}$ Fifty houses with latrines (casehouses) and 50 with flushing toilets (control-houses) were selected by the use of the Random Integer Generator (https://

*Address correspondence to Oscar H. Del Brutto, School of Medicine, Universidad Espiritu Santo - Ecuador, Km 2.5 Vía Puntilla-Samborondon, Samborondon, Ecuador. E-mail: oscardelbrutto@hotmail.com www.random.org/integers/). Each pair was constituted by a selected case-house and the nearest control-house. The study was approved by the Institutional Review Board (IRB) of Universidad Espiritu Santo, Ecuador (FWA: 00028878).

Samples for SARS-CoV-2 RNA identification were obtained from latrines and flushing toilets by swabbing their inner and upper walls with Dacron swabs contained in $1 \mathrm{~mL}$ of RNA Shield ${ }^{\mathrm{TM}}$ (Zymo research, Irvine, CA), which preserves nucleic acid's integrity but inactivates SARS-CoV-2. Following sample collection, tubes were labeled and transported within a cooling package, and then stored at $-80^{\circ} \mathrm{C}$ until analyzed. Operators were blinded to whether samples corresponded to latrines or flushing toilets. Samples were processed in the biosafety level-2 laboratory of UEESBiolab at Universidad Espíritu Santo, Ecuador. RNA extraction was performed using MagMax $^{\mathrm{TM}}$ Microbiome Ultra Kit (Life Technologies, Austin, TX) according to the manufacturer's instructions. SARS-CoV2 RNA detection was performed using real-time (RT)-PCR using Allplex ${ }^{\mathrm{TM}}$ 2019-nCoV Assay (Seegene Inc., Seoul, Republic of Korea). Samples were read with CFX96 Touch RTPCR Detection System (Bio-Rad, Hercules, CA). Readings and data analysis were performed using Seegene Viewer software (Seegene, Inc.). Samples with cycle thresholds $(\mathrm{Ct})<40$ in Cal Red 610 or Quasar 670 (Biosearch Technologies, Novato, CA) fluorophore spectra (corresponding to SARS-CoV-2specific RNA-dependent polymerase and $N$ genes, respectively) were read as positive. By contrast, samples with $\mathrm{Ct}<40$ only in the FAM fluorophore spectra (Integrated DNA Technologies, Coralville, IA) (corresponding to the $E$ gene) were considered negative because of non-specificity for SARS-CoV-2.

Because the house was the unit of analysis, we selected covariates that may suggest or influence household SARS-CoV2 transmission, such as the presence of at least two seropositive subjects in the house, persons living in the house, and bedrooms per house. In addition, we took into account the economic status of the family (stratified according to incomes below or above the basic wage [467 US\$] of all family members with a job).

Data analyses were carried out by using STATA version 16 (College Station, TX). Continuous variables were compared by 


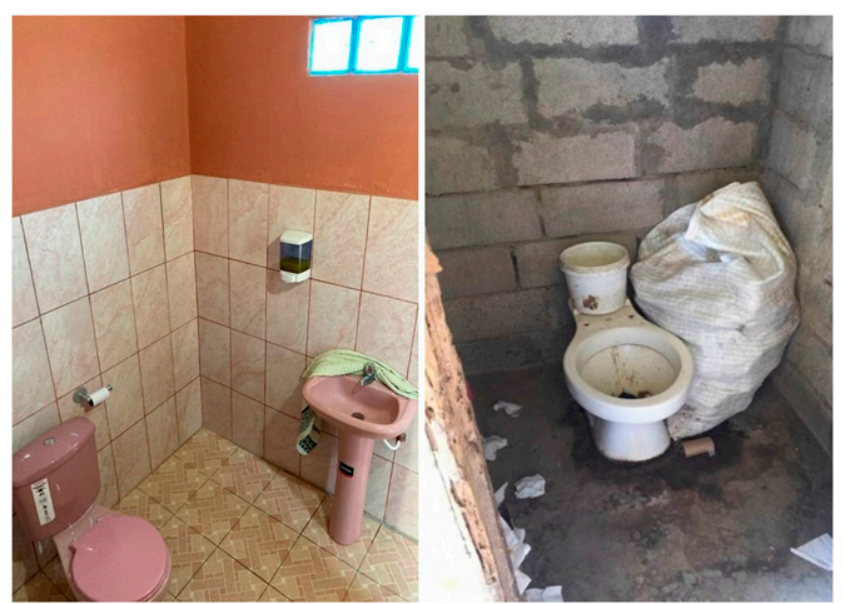

FIGURE 1. Characteristics of bathrooms with flushing toilets (left panel) and latrine cabins (right panel) in Atahualpa. Differences in sanitation are evident between these facilities. Bathrooms have an incorporated piped water sink and most often have disinfecting fluids for handwashing. By contrast, latrines do not have incorporated pipe water sinks and are under poor hygienic conditions, toilet papers are accumulated on open bags or all over the floor, and there is macroscopic evidence of fecal material in some of their inner walls. This figure appears in color at www.ajtmh.org.

linear models and categorical variables by the $x^{2}$ or Fisher's exact test as appropriate. McNemar's test for correlated proportions was used to assess differences in SARS-CoV-2 RNA presence across latrines and flushing toilets. A conditional logistic regression model, adjusted for the aforementioned covariates, was fitted to assess the independent association between SARS-CoV-2 RNA in the swabbed samples and case-control status.

Two swabbed samples, one from a case-house and the other from a control-house, disclosed invalid results. Because those houses had been allocated to two different pairs, four houses were excluded from analysis. A total of 529 individuals inhabited in the 96 remaining houses, including 261 in 48 case-houses and 268 in 48 control-houses. The mean $( \pm S D)$ persons per house was $5.4 \pm 2.6$ in case-houses versus $5.6 \pm$ 3.1 in control houses; $P=0.733$. However, the mean $( \pm S D)$ number of bedrooms per house was lower in case-houses than in control-houses $(2.3 \pm 1$ versus $2.8 \pm 1.1 ; P=0.022)$. A total of $23(48 \%)$ case-houses and $27(56 \%)$ control-houses had family incomes above the basic wage $(P=0.414)$.

Of the aforementioned 529 individuals, 317 (60\%) were aged $\geq 18$ years and eligible for determination of SARS-CoV-2 antibodies (children were excluded as per IRB suggestion). Of 317 candidates, 290 (91\%) underwent a lateral flow-based SARS-CoV-2 antibody testing (BIOHIT Health Care Ltd., Cheshire, United Kingdom). The remaining 27 individuals declined consent. The number of tested subjects did not differ between those living in case- and control-houses (146/261 versus $144 / 268 ; P=0.610)$. A total of $141(49 \%)$ of 290 individuals evaluated for the presence of SARS-CoV-2 antibodies were positive. Of them, 84/146 (57\%) lived in case-houses and $57 / 144(40 \%)$ in control-houses $(P=0.002)$. Likewise, two or more seropositive individuals were found in 30 case-houses and in 18 control-houses (63\% versus $38 \% ; P=0.014$ ).

Twenty-four case-houses and 12 control-houses had SARS-CoV-2 RNA in swabs obtained from latrines and

flushing toilets, respectively (Supplemental File). Matchedpair data disclosed 28 concordant pairs (eight pairs in which both the latrine and the flushing toilet were positive, and 20 pairs in which neither were positive), as well as 20 discordant pairs; in $16(80 \%)$ of these pairs, the latrine was positive, but the flushing toilet did not. The odds ratio $(\mathrm{OR})$ for the presence of SARS-CoV-2 RNA in latrines compared with flushing toilets was 4.0 (95\% Cl: 1.29-16.4, $P=0.014$; McNemar's test). A conditional (fixed-effects) logistic regression model demonstrated that the association between having a latrine and SARS-CoV-2 RNA was highly significant (OR: 4.82; 95\% Cl: 1.38-16.8; $P=0.014)$. None of the included covariates remained significant in this model (Table 1 ).

This study shows that latrines have almost five times the odds of containing SARS-CoV-2 RNA than their paired flushing toilets, and provide support for their potential role as reservoirs of SARS-CoV-2 RNA. Fecal-oral transmission of SARS-CoV-2 infection is also suggested by this study, disclosing a higher number of seropositive subjects among those living in houses with latrines. The opposite, that is, that latrines had more often SARS-CoV-2 RNA than flushing toilets because more infected people used the former, cannot be totally ruled out. However, there was no other apparent reason explaining the higher prevalence of seropositive individuals in houses with a latrine when compared with those with a flushing toilet. On the other hand, the assumption that latrines are a surrogate of poverty and household crowding-favoring SARS-CoV-2 transmission-may not apply to the study population, inasmuch as income status of families living in case- and control-houses were similar, and both were inhabited by roughly the same number of persons. Cultural factors and lack of basic home facilities may account for the continued use of latrines in some houses. As mentioned earlier, handwashing facilities (sinks) were available only at households with flush toilets, whereas houses with latrines have only one faucet at their backyards, which is mostly used to collect water in buckets or jars. The lack of handwashing facilities in houses with latrines may discourage people to wash hands after defecation, which in turn may possibly contribute to enhance transmission if viable SARS-CoV-2 is present. Poor maintenance of latrines also enhances their possibility to be potential foci of contamination from infective stools.

As previously mentioned, some studies have demonstrated persistence of SARS-CoV-2 shedding in feces. ${ }^{7-9}$ Whether these viral particles are viable and how long they will be infective in latrine walls is not known, but it has been suggested that, under specific circumstances-such as dark environments and

\section{TABLE 1}

Conditional logistic regression model (for matched paired data) showing a significant independent association between the presence of SARS-CoV-2 RNA in swabs from inner and upper walls of randomly selected open latrines (case-houses) versus paired flushing toilets (control-houses)

\begin{tabular}{lccc}
\hline \multicolumn{1}{c}{ Case-control status } & Odds ratio & $95 \% \mathrm{Cl}$ & $P$-value \\
\hline SARS-CoV-2 real-time-PCR & 4.82 & $1.38-16.8$ & $0.014^{*}$ \\
Income & 0.93 & $0.37-2.33$ & 0.884 \\
Number of bedrooms per house & 0.66 & $0.41-1.04$ & 0.076 \\
Number of persons per house & 0.95 & $0.81-1.12$ & 0.542 \\
SARS-CoV-2-seropositive subjects & 2.17 & $0.72-6.59$ & 0.169 \\
\hline
\end{tabular}


in nonporous materials-SARS-CoV-2 can remain viable in fomites for several weeks, ${ }^{11}$ In addition, disposal of toilet paper in open waste bins or on the floor of the cabin may increase the risk of fecal transmission of the virus. ${ }^{12}$ In this view, a recent study from rural China suggested that the use of pit latrines may be a source of fecal transmission of SARS-CoV-2, either by direct contagion of humans with contaminated feces or through intermediate animal hosts, that is, bats. ${ }^{13}$

In this study, a sizable proportion of flushing toilets (12/48) also had SARS-CoV-2 RNA. Flushing toilets can generate fecal aerosols that spread SARS-CoV-2 RNA to the air and internal plumbing, and some of them may even remain adhered to their walls. ${ }^{14,15}$ However, incorporated pipe water sinks in bathrooms motivate people to wash their hands after defecation. This practice may reduce the risk of fecal-oral transmission of the infection, as suggested by the lower number of SARS-CoV2-seropositive individuals among those living in houses with flushing toilets.

Unbiased selection of study houses, blinded reading of samples, and proper selection of models for data analyses argued for the strengths of our results. Nevertheless, the study has limitations. Infection status of children was missed, and we cannot be sure on how it could have influenced the seroprevalence of the entire family. In addition, we did not evaluate fecal samples from the inhabitants of included houses. It cannot be concluded if SARS-CoV-2 RNA present in swabs from latrines and flushing toilets corresponded to viable, infective virus. However, this possibility cannot be ruled out.

In summary, SARS-CoV-2 RNA is highly prevalent in latrines, which may represent active infection foci, as suggested by increased rates of seropositivity among individuals living in such houses. These findings open new avenues of research for evaluating the actual role of latrines in human contagion at different settings. Obviously, transmission of the virus through respiratory droplets is the principal source of contagion, but fecal-oral contagion cannot be ruled out. Preventive measures have focused on the use of face masks and social distancing, and little attention has been paid to a potential fecal route of transmission that requires other measures. Frequent disinfection of latrines (and flushing toilets) as well as compulsory handwashing should be recommended to reduce the potential likelihood of fecal contamination. ${ }^{16}$ Also, given the frequency in which SARS-CoV-2 RNA was found, latrines could serve as sentinel places for surveillance of transmission levels.

Received October 22, 2020. Accepted for publication December 29, 2020.

Published online January 13, 2021.

Note: Supplemental file appears at www.ajtmh.org.

Acknowledgment: The American Society of Tropical Medicine and Hygiene has waived the Open Access fee for this article due to the ongoing COVID-19 pandemic.

Disclosure: The study was supported by Universidad Espíritu Santo, Ecuador. The sponsor had no role in the design of the study, nor in data collection or analyses.

Authors' addresses: Oscar H. Del Brutto, School of Medicine, Universidad Espíritu Santo, Samborondón, Ecuador, E-mail: oscardelbrutto@ hotmail.com. Aldo F. Costa and Bettsy Y. Recalde, Community Center, The Atahualpa Project, Atahualpa, Ecuador, E-mails: aldocosva_01@hotmail.com and bettsyr@hotmail.es. Robertino M. Mera, Department of Epidemiology, Gilead Sciences, Inc., Foster City, CA, E-mail: rmm17189@gmail.com. Derly Andrade-Molina and Juan C. Fernández-Cadena, Omics Sciences Laboratory, Universidad Espíritu Santo-Ecuador, Samborondón, Ecuador, E-mails: dmandrademolina@ uees.edu.ec and fernandezjuan@uees.edu.ec. Héctor H. García, Department of Microbiology, Center for Global Health, Universidad Peruana Cayetano Heredia, Lima, Perú, E-mail: hgarcia@jhsph.edu.

This is an open-access article distributed under the terms of the Creative Commons Attribution (CC-BY) License, which permits unrestricted use, distribution, and reproduction in any medium, provided the original author and source are credited.

\section{REFERENCES}

1. Amigo I, 2020. Indigenous communities in Brazil fear pandemic's impact. Science 368: 352.

2. Miller MJ, Loaiza JR, Takyar A, Gilman RH, 2020. COVID-19 in Latin America: novel transmission dynamics for a global pandemic? PloS Negl Trop Dis 14: e0008265.

3. Del Brutto OH, Costa AF, Mera RM, Recalde BY, Bustos JA, García HH, 2020. SARS-CoV-2 in rural Latin America. A population-based study in coastal Ecuador. Clin Infect Dis (Epub ahead of print). Available at: https://doi.org/10.1093/cid/ ciaa1055.

4. Del Brutto OH, Costa AF, Mera RM, Recalde BY, Bustos JA, García HH, 2020. Late incidence of SARS-CoV-2 infection in a highly endemic remote rural setting. A prospective populationbased cohort study. Pathog Glob Health 114: 457-462.

5. Del Brutto OH, Costa AF, García HH, 2020. Incident SARS-CoV-2 infection and a shared latrine. Am J Trop Med Hyg 103: 941-942.

6. Del Brutto OH, Mera RM, Recalde BY, Costa AF, 2020. Social determinants of health and risk of SARS-CoV-2 infection in community-dwelling older adults living in a rural Latin American setting. J Community Health (Epub ahead of print). Available at: https://doi.org/10.1007/s10900-020-00887-9.

7. Chen $Y$ et al., 2020. The presence of SARS-CoV-2 RNA in the feces of COVID-19 patients. J Med Virol 92: 833-840.

8. Wong MCs, Huang J, Lai C, Ng R, Chan FKL, Chan PKS, 2020. Detection of SARS-CoV-2 in fecal specimens of patients with confirmed COVID-19: a meta-analysis. J Infect 81: e31-e38.

9. Park SK, Lee CW, Park DI, Woo HY, Cheong HS, Cheol H, Ahn K, Kwon M, Joo EJ, 2020. Detection of SARS-CoV-2 in fecal samples from patients with asymptomatic and mild COVID-19 in Korea. Clin Gastroenterol Hepatol (Epub ahead of print). Available at: https:// doi.org/10.1016/..cgh.2020.06.005.

10. Del Brutto OH, Mera RM, Castillo PR, Del Brutto VJ, 2018. Key findings from the Atahualpa project: what should we learn? Expert Rev Neurother 18: 5-8.

11. Riddell S, Goldie S, Hill A, Eagles D, Drew TW, 2020. The effect of temperature on persistence of SARS-CoV-2 on common surfaces. Virol J 17: 145.

12. Sun S, Han J, 2020. Unflushable or missing toilet paper, the dilemma for developing communities during the COVID-19 episode. Environ Chem Lett (Epub ahead of print). Available at: https://doi.org/10.1007/s10311-020-01064-z.

13. Liu L, Hu J, Hou Y, Tao Z, Chen Z, Chen K, 2020. Pit latrines may be a potential risk in rural China and low-income countries dealing with COVID-19. Sci Total Environ (Epub ahead of print). Available at: https://doi.org/10.1016/j.scitotenv.2020.143283.

14. Li YY, Wang JX, Chen X, 2020. Can a toilet promote virus transmission? From a fluid dynamics perspective. Phys Fluids 32: 065107.

15. Kang $\mathrm{M}$ et al., 2020. Probable evidence of fecal aerosol transmission of SARS-CoV-2 in a high-rise building. Ann Intern Med 173: 974-980.

16. Meng X, Huang X, Zhou P, Li C, Wu A, 2020. Alert for SARS-CoV-2 particles caused by fecal aerosols in rural areas in China. Infect Control Hosp Epidemiol 41: 987. 